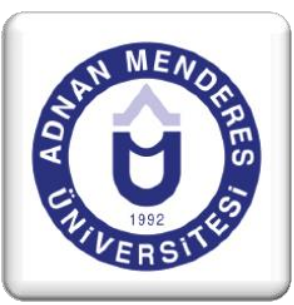

\title{
Türk Bankacılık Sektörü İçin Karşılaştırmalı Performans Analizi
}

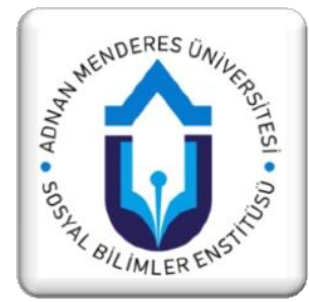

\author{
Mehmet Fatih ACAR ${ }^{\text {a }}$, Taptuk Emre ERKOÇ \\ Bülent YILMAZ
}

\begin{abstract}
Özet
Ulusal ve uluslararası ekonomilerde finansal aracıllk faaliyetlerinin vazgeçilmez unsuru olan bankalar, Türkiye'nin de finansal pazarında önemli roller oynamaktadırlar. Dolayısıyla bankaların etkin ve verimli çalışmaları sadece kendileri için değil aynı zamanda müşterileri ve ülke ekonomisi açısından da çok önemlidir. Bu çalışmada, Veri Zarflama Analizi yöntemi ile Türkiye'de faaliyet gösteren belirli bankaların etkinlik puanları hesaplanmıştır. Analizlerde girdi olarak bankaların şube sayısı, personel sayısı ve toplam aktifleri, çıktı olarak ise kar ve toplanan mevduat göz önünde bulundurulmuştur. İlgili veriler kurumların 2009-2013 yılları arasındaki bilgilerinden oluşmaktadır. Bankalar sahiplik durumlarına ve işleyişine göre yerli ve yabancı özel bankalar ile kamu ve katılım bankaları olmak üzere dört grupta toplanmıștır. Analiz sonuçlarına göre en etkin banka grubu kamu bankaları olmuştur ve bunu sırasıyla yerli-özel bankalar, katılım bankaları ve yabancı-özel bankalar izlemiştir. Ayrıca çalışmada, etkinlik analizi sonuçları Türkiye ekonomisi açısından değerlendirilmiştir.
\end{abstract}

Anahtar Kelimeler: Veri Zarflama Analizi, Teknik Etkinlik, Bankacılık, Türkiye

\section{A Comparative Analysis of Performance for the Turkish Banking Sector}

\begin{abstract}
Banks are the important part of financial sector in Turkish economy like international ones. Therefore efficiency of banks are important not only for them but also for their customers and national economy. In this study, efficiency scores of some banks in Turkey are calculated with Data Envelopment Analysis. For this research inputs are the number of personnel, the number of branch and total assets; also outputs are profit and total deposits. This information are related with during 2009-2013 period. According to ownership and process, banks are classified as public, domestic-private, foreign-private and participation ones. Results show that the most efficient banking group is public, then domestic-private, participation and foreign-private banking groups, respectively. Additionally, outcomes are discussed in terms of Turkish economy.
\end{abstract}

Keywords: Data Envelopment Analysis, Technical Efficiency, Banking Sector, Turkey

\footnotetext{
a Gediz Üniversitesi, Lojistik Yönetmi Bölümü,Yrd.Doç.Dr., mehmet.acar@ gediz.edu.tr.

${ }^{\mathrm{b}}$ Queen Mary, University of London, Dr. Araş. Gör., t.erkoc@qmul.ac.uk

${ }^{c}$ Kara harp Okulu, İşletme Bölümü, Dr. Öğr. Gör., byilmaz@kho.edu.tr
} 


\section{Literatür Taraması}

Finansal sistem içerisinde faaliyet gösteren ve ulusal ve uluslararası ekonomilerde finansal aracılık faaliyetlerinin vazgeçilmez unsuru olan bankalar, Türkiye'nin de finansal pazarında önemli roller oynamaktadırlar. Bankacılık sektörü ülkelerin içinde bulunduğu ekonomik, sosyal ve siyasal durumlara göre değişik trendler izlemektedirler.

Türkiye'de bankacılık sektörü finansal sistemde ağırlıklı bir paya sahiptir. Son yıllarda banka dışı finansal kurumların sayısında ve büyüklüğünde artış olmasına rağmen finansal sistem içindeki toplam aktiflerin yaklaşık \%90'ı bankacılık sektörüne aittir (Türkiye Bankalar Birliği, 2005:12).

Yeni düzenlemelerin ve teknolojideki ilerlemenin bir sonucu olarak, finansal piyasalarda hızlı bir değişim yaşanmaktadır. Bu kapsamda; ulusal ve uluslararası piyasalar arasında engeller ortadan kalkmakta ve piyasalar küreselleşmektedir.

Bankalar hukuki yapıları, fonksiyonları, sermaye yapıları vb. özellikleri dikkate alınarak çeşitli alanlara ayrılmaktadır. Bunlardan bazıları; Kamu Bankaları, Özel Bankalar, Yerli Sermayeli Bankalar, Yabancı Sermayeli Bankalar, Merkez Bankası, Ticaret Bankaları, Yatırım Bankaları, Kalkınma Bankaları ve Katılım Bankalarıdır. Söz konusu banka çeşitlerinden ticaret bankaları ya da diğer bir ismi ile mevduat bankaları, mevduat kabul eden ve mevduatı değişik alanlarda kredi ve iştirak aracı olarak kullanan kurumlardır şeklinde tanımlanabilir. (Tolon, 2004). Fonksiyonu açısından diğer tüm banka çeşitlerinden ayrılan, Türkiye'de ve Dünya'da özelikle son yıllarda inançları dolayısıyla faiz geliri elde etmek istemeyen insanların başvurduğu banka çeşidi ise katılım bankalarıdır. Katılım bankaları, faiz kaygısından dolayı bankalara gitmeyen fonları ekonomiye kazandırmak ve sermaye sahiplerinin birikimlerini güvenle saklamalarına ve değerlendirmelerine yardımcı olmak amacıyla kurulmuştur. Katılım bankalarında faiz değil, kardan veya zarardan pay alınması esası uygulanmaktadır. Kısaca katılım bankaları, alternatif finansman yöntemi hizmetleri sunarak bankacılık sektöründe faaliyette bulunan, reel ekonomiyi finanse eden ve bankacılık hizmetleri sunan kuruluşlardır.

Ekonomik koşullar bankaların kaynaklarını en etkin şekilde kullanmaya zorlamaktadır. Bunu sağlamak için bankaların rekabet ettikleri sektör içinde performanslarını değerlendirmeleri ve etkinlik ve verimliliklerini yetenekleri ölçülerinde en üst seviyeye çıkarmaları gerekmektedir. Bankaların istenilen performanslara ulaşılıp ulaşılamadığının ölçülmesinde etkinlik ve verimlilik analizleri çok önemli yönetim araçlarıdır. Bankacılık için etkinlik ve verimlilik analizleri sadece kendi sektörleri için değil ülke ekonomileri açısından da büyük önem taşımaktadır, çünkü bu sektör diğer ekonomik sektörlerden farklı olarak kaynak dağılımını belirleyen finansal aracılık görevi üstlenmiştir. Bankacılık sektörü bu açıdan ekonomik gelişimde merkezi bir durumdadır. Bu nedenle bankacılık sektörünün performans analizinin yapılabilmesi için etkinlik ve verimlilik kriterlerinin analizi gereklidir.

Bankacılık sisteminin etkinliği ve verimliliği üzerine yapılmış çok sayıda bilimsel çalışma bulunmaktadır. Literatürde etkinlik genelde maliyetlerin minimize edilip edilmediği veya karın maksimize olup olmadığını gösteren işlem verimliliğinin tahmini için kullanılmaktadır (Berger, Hunter, v.d., 1993; Maudos ve Pastor, 2003).

Küreselleşmenin ve rekabetin giderek arttığı, değişimlerin çok hızlı yaşandığı günümüz finansal piyasalarında yöneticiler, yatırımcılar ve bankalar çeşitli finansal ürün ve hizmetlerin daha verimli hale nasıl getirileceği konusunda daha fazla çalışmaktadırlar. Verimliliğin artırılması konusuna politikacılar, bankacılar ve araştırmacı akademisyenler 
yoğun bir şekilde eğilmişlerdir. Sufian (2009), Iş̧k (2008), Rezitis (2007), Işık ve Hasan (2002), Das ve diğerleri (2009), Mercan ve diğerleri (2003) gibi farklı bankaların verimlilik düzeylerini incelemek üzere alanda birçok çalışma yapılmıştır.

Bankaların büyüklüğü genellikle varlıklarının miktarı ile açıklanır. Jackson ve Fethi (2000), Mercan ve diğg. (2003) çalışmalarında yapmış olduğu analizlerde verimlilik ile banka büyüklüğünün etkisi arasında pozitif bir ilişki bulmuştur. Işık ve Hasan (2002)'de yapılan çalışmalarında ise banka büyüklüğü ile verimlilik arasında negatif bir ilişki tespit etmiştir. Chen ve arkadaşlarının 2005 yılında yapmış olduğu bir çalışmada ise büyük ve küçük bankaların, orta büyüklükteki bankalara göre daha verimli oldukları bulunmuştur. Yapılan çalışmalar incelendiğinde banka verimliliğin hangi unsurlardan etkilendiğine dair ortak bir kanı olmamasına rağmen büyük bankaların küçük ve orta ölçekli bankalara göre daha verimli oldukları düşüncesi yaygındır.

Bankaların büyüklüğünün yanı sıra halka açıklığı ile verimlilik arasındaki ilişkiler analiz edildiğinde de genellikle anlamlı bir ilişki olmadığı ortaya çıkmıştır. Sufian (2009), Havrylchyk (2006) ve Mamatzakis ve diğ. (2008) halka açıklığın veya kamu bankası olmanın verimlilik üzerinde bir etkisi olmadığını ortaya koymuşlardır.

Verimlilik ile ilişkili olduğu düşünülen bankaların sahiplik durumları hakkında yapılan çalışmalarda değişik sonuçlara ulaşılmıştır. Jackson ve Fethi (2000) kamu bankalarının diğer bankalara oranla daha verimsiz olduklarını ortaya koymuşlardır. Işık ve Hasan (2002) çalışmasında ise kamu bankalarının daha düşük maliyetle çalıştıkları ve verimlilik düzeylerinin diğer bankalara göre daha üst düzeyde olduğunu dile getirmişlerdir. Mercan ve diğerleri (2003) çalışmalarında bankaları kamu, özel ve yabancı sermayeli olarak sınıflandırarak kamu bankalarının daha düşük performansla çalıştığını belirtmişlerdir. Sufian (2009) yaptığı çalışmada yabancı bankaların yerli bankalara göre daha verimli olabileceğini göstermiştir. Jackson ve diğ. (1998) Türkiye'de 1992-1996 dönemlerini incelediklerinde özel ve yabancı sermayeli bankaların daha fazla büyüme gösterdikleri ve verimli olduklarını belirtmiş̧lerdir. Havrylchyk (2006)' da yaptı̆̆ 1 çalışmada diğer çalışmalara benzer bir kanıya vararak yabancı sermayeli bankaların kamu bankalarına oranla daha yüksek düzeyde verimliğe sahip olduğunu belirtmiştir.

Bankacılık sektöründe verimlilik yöntemleri genel olarak üç gruba ayrılmaktadır. Bunlar rasyo analizi, parametrik yöntemler ve parametrik olmayan yöntemlerdir. Rasyo analizi, tek girdi ile çıktıların birbirleriyle oranlanması sonucu oluşan matematiksel ilişkinin zaman içinde izlenmesi şeklinde uygulanmaktadır. Ancak çok sayıda girdi ve çıktı içeren karar birimlerinde tek rasyoya bakarak karar vermek mümkün değildir. Parametrik yöntemlerde kullanılan gözlem kümesi içinde en iyi performansın regresyon çizgisi sınırı üzerinde olduğu varsayımından hareket edilir. Regresyon çizgisi sınırı üzerinden sapma göstermeyen gözlemler etkindir. Ancak tam etkin gözlemler hatanın sıfır olduğu gözlemlerdir (İnan, 2000). Parametrik olmayan yöntemler ise, doğrusal programlama teknikleri ile etkinlik sınırına olan uzaklığı ölçmektedir. Parametrik olmayan yöntemlerden 1978 yılında Charnes, Cooper ve Rhodes tarafından geliştirilen ve literatürde Veri Zarflama Analizi- Data Envelopment Analysis- (VZA-DEA) olarak bilinen bir yöntemdir. Bu teknikte lineer programlama kullanılarak en iyi davranan gözlemlerden oluşan etkinlik sınırı tespit edilmekte ve tüm gözlemlerin bu sınıra uzaklığı (göreli etkinliği) ölçülmektedir.

\section{Metod}


Veri Zarflama Analizi (VZA) parametrik olmayan bir etkinlik analiz yöntemidir. Bu analizde belirli bir teknoloji seviyesi altında her bir karar verme biriminin $m$ tane girdisi, $n$ tane çıktısı vardır. $X_{i j} j .(j=1,2, \ldots, k)$ karar biriminin $m$ tane olan girdilerinden i'ninci $(\mathrm{i}=1,2, \ldots \ldots, \mathrm{m})$ girdi miktarını işaret eder. Aynı zamanda $\mathrm{Y}_{\mathrm{sj}}$ ise $\mathrm{j} .(\mathrm{j}=1,2, \ldots, \mathrm{k})$ karar biriminin $\mathrm{n}$ tane olan çıktılarından s'ninci $(\mathrm{s}=1,2, \ldots, \mathrm{n})$ çıktı miktarını işaret eder. $\mathrm{u}_{\mathrm{r}}$ $(\mathrm{r}=1,2 \ldots \mathrm{n})$ ve $\mathrm{w}_{\mathrm{i}}(\mathrm{i}=1,2 \ldots \mathrm{m})$ değişkenleri her bir girdi ve çıktı miktarının ağırlıklarıdır. Herhangi bir karar biriminin verimliliği ağılıklandırılmış çıktı toplamlarının, ağırlıklandırılmış girdi miktarına oranıdır. Dolayısıyla verimliliğin matematiksel model olarak gösterimi aşağıda verilmiştir.

$\operatorname{Max}=\frac{\sum_{r=1}^{n} u_{r} Y_{r 0}}{\sum_{i=1}^{m} w_{i} X_{i 0}}$

(1)

Kisitlar;

$\frac{\sum_{r=1}^{n} u_{r} Y_{r j}}{\sum_{i=1}^{m} w_{i} X_{i j}} \leq 1 \quad \mathrm{j}=1,2 \ldots \mathrm{k}$

$\boldsymbol{u}_{\boldsymbol{r}}$ ve $\boldsymbol{w}_{\boldsymbol{i}} \geq 0 \quad(r=1,2, \ldots \ldots, n)$ ve $(i=1,2, \ldots \ldots, m)$.

(3)

$\mathrm{Bu}$ model en iyi etkinlik değeri için etkinlik skorlarının en fazla 1 olduğu kısıtı altında en uygun u ve w değerlerini bulmaya çalışır. Sonsuz tane sonuçtan kaçınmak (Coelli ve diğerleri, 2005:163) için kurgulanan Charnes-Cooper modeli aşağıda gösterilmiştir.

$\operatorname{Max}=\sum_{r=1}^{n} \mu_{r} Y_{r 0}$

Kisitlar

$\sum_{\mathrm{i}=1}^{\mathrm{m}} \mathrm{w}_{\mathrm{i}} \mathrm{X}_{\mathrm{i} 0}=1$,

$\sum_{r=1}^{n} \mu_{r} Y_{r j}-\sum_{i=1}^{m} w_{i} X_{i j} \leq 0$

(6)

$\mu_{r}$ ve $w_{i} \geq 0 \quad(r=1,2, \ldots \ldots, n)$ ve $(i=1,2, \ldots \ldots, m)$

Lineer programlamanın dual özelliği kullanılarak yukarıdaki modelin değişken ölçekli formülasyonu ise aşağıda belirtilmiştir.

$\operatorname{Min} \theta$

Kisitlar

$\sum_{j=1}^{k} \lambda_{j} X_{i j} \leq \theta X_{\mathrm{i} 0} \quad(i=1,2 \ldots m)$

(9) 


$$
\begin{aligned}
& \sum_{j=1}^{k} \lambda_{j} Y_{r j} \geq \mathrm{Y}_{\mathrm{r} 0} \quad(r=1,2 \ldots n) \\
& \sum_{j=1}^{k} \lambda_{j}=1, \text { for } \mathrm{j}=1,2 \ldots \mathrm{k}
\end{aligned}
$$

Burada $\theta$ bir çarpan, $\lambda$ ise $\mathrm{k} x 1$ vektörlü sabit sayılardır. Modelin sonucunda her bir karar biriminin etkinlik değeri ile ilgili olarak $\Theta$ s değeri bulunur. Dolayısıyla $\Theta$ değeri birden küçük veya bire eşittir. $\Theta$ değerinin 1 eşit olması karar biriminin teknik olarak etkin olduğunu gösterir (Farell,1957).

Bunlara ek olarak, Koopman (1951) modeli biraz daha genişleterek en iyi sonucu elde etmek için girdi ve çıktılardaki eksik ve fazlalıkları belirlemeye çalışmıştır. Dolayısıyla, matematiksel modele boş değişkenler eklenerek yeni model oluşturulmuştur.

$\operatorname{Min} \theta_{0}-\varepsilon\left(\sum_{i=1}^{m} \mathrm{~s}_{i}^{-}+\sum_{r=1}^{n} \mathrm{~s}_{r}^{+}\right)$

Kisitlar

$$
\sum_{j=1}^{k} \lambda_{j} X_{i j}+s_{i}^{-}=\theta \mathrm{X}_{\mathrm{i} 0} \quad(i=1,2, \ldots \ldots, m)
$$

$$
\sum_{j=1}^{k} \lambda_{j} Y_{r j}+\mathrm{s}_{r}^{+}=\mathrm{Y}_{\mathrm{r} 0} \quad(r=1,2, \ldots \ldots, n)
$$

$$
\mathrm{s}_{r}^{+}, \mathrm{s}_{i}^{-}, \lambda_{j} \geq 0 \quad \mathrm{j}=1,2, \ldots, \mathrm{k}
$$

Burada $s_{r}^{+}$ve $s_{i}^{-}$boş değişkenlerdir ve eşitsizlikleri denkleme dönüştürmede kullanılmışlardır. $\mathrm{s}_{\mathrm{r}}^{+}$değişkeni her sonucun $\mathrm{Y}_{\mathrm{r} 0} \leq \sum \lambda_{\mathrm{j}} \mathrm{Y}_{\mathrm{rj}}$ denklemini sağlaması gerektiğini işaret eder, $s_{i}^{-}$ise kullanılan her bir girdinin $\sum \lambda_{j} X_{i j} \leq X_{i 0}$ denklemini sağlaması gerektiğine işaret eder. Sonuç olarak, lineer programlama modellerinin analizi ile ulaşılan $\Theta_{0}=1$ olduğu durumda her bir karar vericinin belirlenen girdi ve çıktı şartlarında görece $100 \%$ etkin olduğu düşünülür (Erkoc, 2012).

\section{Analiz}

Bu araştırmada Türkiye'de faaliyet gösteren 15 banka göz önünde bulundurulmuştur. Bankalar seçilirken kurumların büyüklüğü ve piyasada bilinirliliği göz önünde 
bulundurulmuştur. Buna göre 3 kamu bankası, 4 yerli-özel banka, 4 katılım bankası ve 4 yabancı-özel banka seçilmiştir. Bu bankalar için literatüre uygun olarak girdi ve çıktılar belirlenmiştir. Şube sayısı, personel sayısı ve toplam aktifler girdi olarak, kar ve toplanan mevduat ise çıtıt olarak düşünülmüştür. Bu veriler 2009 ile 2013 yılları arasındaki bilgileri içermektedir. Veri Zarflama Analizi ile bu veriler analize tabi tutulmuştur.

Türkiye'de 2009-2013 yılları arasında belirlenen bankalar için verimlilik hesaplamaları yapıldığında sabit ölçekli etkinlik sonuçlarının ortalaması $\% 84$ olarak tespit edilmiştir. Hem girdi odaklı hem de çıtı odaklı analizlerde en küçük etkinlik oranı 0.59 , en fazla 1 olmuştur. Standart sapmanın 0.11 olduğunu da dikkate alınırsa, söz konusu bankaların önemli bir bölümünün etkinlik performansları için $\% 73$ ile $\% 95$ arasında değiştiği öne sürülebilir.

\begin{tabular}{|l|l|l|l|l|}
\hline $\begin{array}{l}\text { Teknik Etkinlik } \\
\text { Değeri }\end{array}$ & Ortalama & $\begin{array}{l}\text { Standart } \\
\text { Sapma }\end{array}$ & En Küçük & En Büyük \\
\hline Girdi Odaklı & 0.84 & 0.11 & 0.59 & 1 \\
\hline Çıkt Odaklı & 0.84 & 0.11 & 0.59 & 1 \\
\hline
\end{tabular}

Tablo 1: Sabit Ölçekli Etkinlik Sonuçları

Aynı yıllar için yapılan değişken ölçekli analizde ise her iki ölçek içinde etkinlik sonuçlarının ortalaması \%86 olarak tespit edilmiştir. Girdi odaklı analizlerde en küçük etkinlik oranı 0.63 , en fazla 1 olmuştur. Çıktı odaklı analizlerde ise en küçük etkinlik oranı 0.62 , yine en fazla 1 olmuştur. Aynı zamanda ortalama etkinlik sonuçların $2 \%$ arttığı ve en düşük etkinlik değerine sahip bankanın da 4\%'luk bir iyileşme yaşadığı ifade edilebilir.

\begin{tabular}{|l|l|l|l|l|}
\hline $\begin{array}{l}\text { Teknik Etkinlik } \\
\text { Değeri }\end{array}$ & Ortalama & $\begin{array}{l}\text { Standart } \\
\text { Sapma }\end{array}$ & En Küçük & En Büyük \\
\hline Girdi Odaklı & 0.86 & 0.11 & 0.63 & 1 \\
\hline Çıktı Odaklı & 0.86 & 0.11 & 0.62 & 1 \\
\hline
\end{tabular}

Tablo 2: Değişken Ölçekli Etkinlik Sonuçları

Çalışmanın buraya kadar olan kısmında hem sabit hem de değişken ölçekli analizler yapılmıştır. Fakat genellikle literatürde ki araştırmalar değişken ölçekli olduğu için bundan sonraki analizlerde değişken ölçek kullanılmıştır. Aynı şekilde şu ana kadar girdi ve çıktı odaklı analizler göz önünde bulundurulmuştur. İlerleyen aşamalarda literatüre sadık kalınarak sadece girdi odaklı analizlere yer verilecektir.

\section{Banka Çeşitleri ve Etkinlik}

Makalenin önemli sonuçlarından birisi de banka çeşitleri ve etkinlik performansı arasındaki ilişkiye ait bir takım bulgular sunmasıdır. Araştırmaya dahil edilen 15 banka; kamu, yerli-özel, katılım ve yabanc1-özel olarak 4 ana kategoriye ayrıldıktan sonra ortalama etkinlik değerleri baz alınarak aşağıdaki Tablo 3'de ifade edilen sonuca ulaşılmıştır. Banka 
grupları arasında kamu bankaları grubu en etkin ortalamaya sahiptir. Bunu sirasiyla yerliözel firmalar, katılım bankaları ve yabancı-özel bankalar grubu takip etmektedir. $\mathrm{Bu}$ noktada dile getirilmelidir ki aşağıdaki tabloda paylaşılan değerler bankaların teknik etkinlik sonuçlarıdır. Dolayısıyla girdi fiyatlarının da dikkate alındığı maliyet etkinliği ya da ekonomik etkinlik açısından bir bilgi içermezler.

\begin{tabular}{|l|l|l|l|}
\hline Kamu & Yerli-Özel & Katılım & Yabancı-Özel \\
\hline 0,92884173 & 0,9116195 & 0,8964241 & 0,7344646 \\
\hline
\end{tabular}

Tablo 3: Banka gruplarının ortalama etkinlik sonuçlar

Şekil 1'de gösterildiği üzere 2009-2013 yılları arasında yabancı özel bankalara ait etkinlik skorları genel olarak diğer bankaların etkinlik skorlarına göre düşüktür (Banka No: 12-15). Kamu bankaları ise çoğunlukla diğer bankalara göre daha etkindirler. (Banka No: 13)

\section{Etkinlik Skorları}

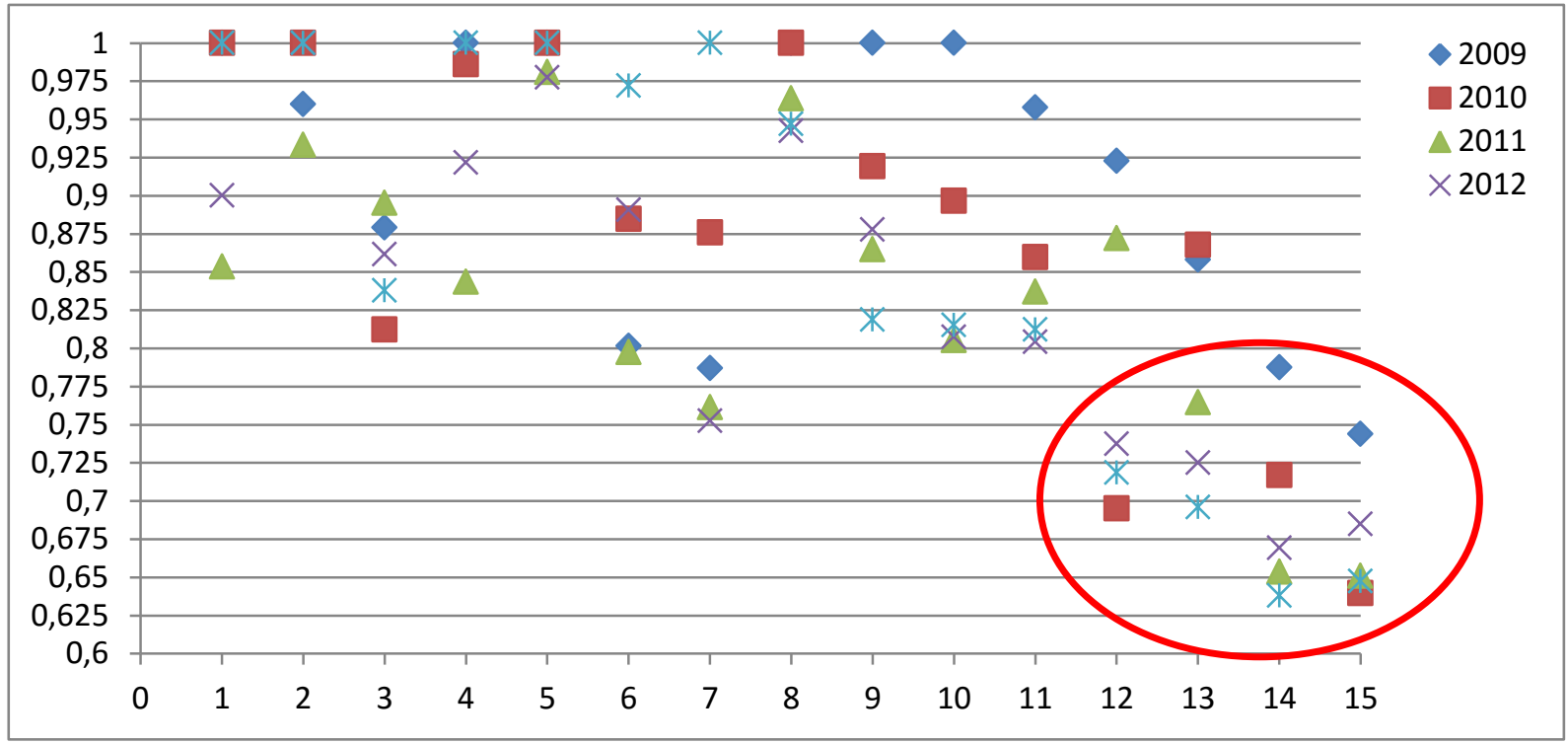

Bankalar

Şekil 1: Banka Etkinlik Sonuçları

\section{Toplam Faktör Verimliliği}


Toplam faktör verimliliği, panel veri setine sahip çalıșmalar için kullanılabilen ve yıllar arasındaki ortalama etkinlikte meydana gelen muhtemel değişimin ne yönde olduğunu gösteren bir araçtır. Bulunan değer eğer 1'in üzerindeyse ortalama etkinliğin yıl içerisinde arttığına, 1'in altında ise de azaldığına işaret eder. $\mathrm{Bu}$ araştırmanın sonuçlarına göre Türkiye'deki bankacılık sektörü ortalama etkinlik açısından düzenli bir iyileşme göstermemiştir. 2009-2010 ve 2011-2012 yıllarında tecrübe edilen etkinlik artış1 diğer yıllarda yerini düşüş eğilimine bırakmıştır. Sektördeki genel sonuçların yanı sıra banka

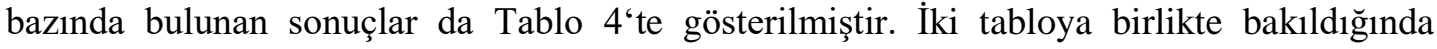
görülecektir ki, bazı istisnai durumlar dışarıda bırakılırsa, sektörde meydana gelen ortalama etkinlik değişiklikleri, bankaların bireysel değişimleri ile de paralellik içerisindedir. Bu anlamda ifade edilebilir ki Periyot 2'de iki banka haricinde diğer bankaların tamamen etkinlik düşüşü yaşaması 2010-2011 yılının bankacılık sektörünü açısından daha dikkatli incelenmesi gerektiğini ortaya koymaktadır.

\begin{tabular}{|l|l|l|l|l|}
\hline Bankalar & Periyot $\mathbf{1}$ & Periyot 2 & Periyot 3 & Periyot 4 \\
\hline Türkiye Cumhuriyeti Ziraat Bankası A.Ş. & 0.9357 & 0.8628 & 1.1968 & 1.0753 \\
\hline Türkiye Halk Bankası A.Ş. & 0.9708 & 1.0627 & 1.0373 & 0.8733 \\
\hline Türkiye Vakıflar Bankası T.A.O. & 1.3418 & 0.9619 & 0.9302 & 1.0038 \\
\hline Akbank T.A.Ş. & 0.9762 & 0.7732 & 1.279 & 1.0765 \\
\hline Türkiye Garanti Bankası A.Ş. & 0.9675 & 0.6922 & 1.2903 & 0.819 \\
\hline Türkiye İş Bankası A.Ş. & 1.5227 & 0.9371 & 0.9523 & 0.6586 \\
\hline Yapı ve Kredi Bankası A.Ş. & 1.0938 & 0.8689 & 1.075 & 1.0598 \\
\hline Albaraka Türk & 1.301 & 0.9747 & 0.9339 & 0.9694 \\
\hline Bank Asya & 1.1623 & 0.7297 & 1.23 & 0.9402 \\
\hline Kuveyt Türk & 1.2239 & 0.6083 & 0.9868 & 0.865 \\
\hline Türkiye Finans & 1.4122 & 0.9123 & 0.9901 & 0.9445 \\
\hline Denizbank A.Ş. & 0.9128 & 1.0256 & 0.9591 & 0.8115 \\
\hline Finans Bank A.Ş. & 1.4116 & 0.9343 & 0.9375 & 1.0226 \\
\hline HSBC Bank A.Ş. & 1.145 & 0.7747 & 1.2031 & 1.0217 \\
\hline ING Bank A.Ş. & 0.8711 & 0.8907 & 1.0011 & 0.8674 \\
\hline Ortalama & 1.1499 & 0.8673 & 1.0668 & 0.9339 \\
\hline
\end{tabular}

Tablo 4 :Toplam Faktör Verimliliği (2009-2013)

(Periyot 1= 2009'dan 2010'a)

\section{6. Önyükleme (Bootstrapping)}

Bootstrapping, istatistiki özellik içermeyen VZA metodu için, sonradan örneklemi kendi kendine çoğaltmak yoluyla (resampling) istatistiki özellik katmak için tasarlanmış bir 
yöntemdir. Biz bu araştırma için, bahsi geçen yöntemi kullanıp bankalar için bulduğumuz etkinlik sonuçlarının istatistiki olarak ne denli güvenilir olduğunu test etmeye çalıştık. Aşağıdaki grafikte, $95 \%$ güven aralığı içerisinde değişen etkinlik skorları kırmızı nokta üst limit, mavi nokta alt limit olarak gösterilmiştir.

Şekil-2'de de görüleceği gibi, ortalama etkinlik skorları 85\%'in üzerinde olan bankalar ile 80\%'in altında olan bankalar, istatistiki olarak da birbirlerinden tamamen ayrılmaktadır. Etkinlik performans $185 \%$ 'in üzerinde olan bankaları bir kaçı istisna hariç ayırt etmek pek mümkün görünmemektedir.. Aynı şekilde etkinlik sonucu $85 \%$ ile $80 \%$ arasında kalan bankalar için de net bir farklılaşma tespit edilememektedir. Diğer önemli bir sonuç ise, etkinlik değeri çok aşağılarda olan bankalar bootstrapping ile dahi $70 \%$ 'in üzerinde bir etkinliğe ulaşamamaktadır. Dolayısıyla bu noktadaki bankalar mevcut girdi-çıktı tercihlerini yeniden gözden geçirmelidirler.

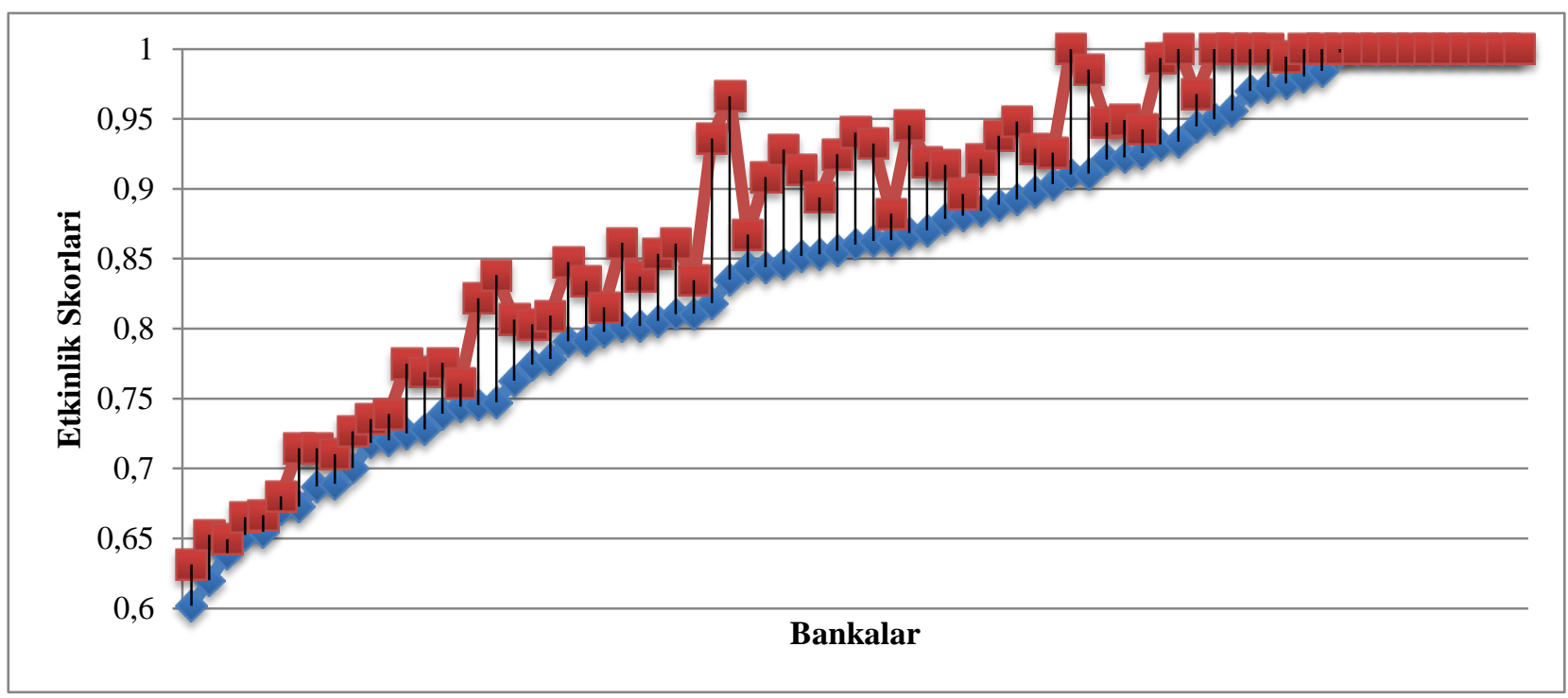

Şekil 2: Bootstrapping Sonucunda Banka Etkinlik Skorları (95\% Güvenilirlik Aralığı)

\section{Sonuç}

Bankac1lık sektörü, bütün dünyada olduğu gibi Türkiye'de de toplam ekonomik faaliyetlerin önemli bir bileşenini oluşturmaktadır. Finansal sistem ile reel ekonomi arasında köprü olma vazifesi de gören bankalar, kendi iç işleyişinin verimliliği açısından son derece önemli bir yapıya sahiptir. Sistem içerisinde var olan verimsiz kaynak kullanımının, hane halklarının gündelik yaşamını olumsuz yönde etkileyeceği gibi, özel sektörün borçlanma tercih ve durumlarını da büyük ölçüde dezavantajı bir mecraya sürükleyebilir. Bu çalışmada, 2009-2013 yılları arasındaki verileri baz alarak yaptığımız araştırma, bankacılık sektöründe hem genel hem de bankaların bireysel etkinlik performansları açısından belli ipuçları sunmaktadır. Sektör, ortalama etkinlik açısından iyi sonuçlara sahip olsa da, özellikle yabancı mülkiyete haiz özel bankaların etkinliklerinin iyi olmadığı tespit edilmiştir. En etkin kurumların ise kamu bankaları olduğu gözükmektedir. Bunu sırasıyla yerli-özel bankalar ile katılım bankaları izlemektedir. Bunun sebebi olarak Türkiye'de yaşanan 2001 ekonomik 
krizinden sonra kamuda özellikle de bankacılık sektöründe uygulanan sert kurallar ve ciddi mali kontrol kamu bankalarının etkinliğini arttırdığı söylenebilir. Ayrıca Türkiye'de son yıllardaki ekonomik istikrarın geçmiş yıllara nazaran daha fazla olması kamu bankalarının karlılı̆̆ına da olumlu etkisi olmuştur. Türkiye'deki bankacılık sektörüne sonradan giren katılım bankaları ile yabancı-özel bankalar ise piyasada yeni yer etmeye başlamışlardır. Dolayısıyla bu bankaların verimliliğinin düşük olması normaldir. Kamu bankalarından sonra gelen yerli-özel bankalar ise uzun süredir piyasada olduklarından verimlilik düzeyleri diğer iki bankaya göre daha etkin olmuştur. Bunun yanı sıra, toplam faktör verimliliği sonuçları, bankacılık sektörünün ortalama etkinlik performanslarının kayda değer bir iyileştirme göstermediğini de ortaya koymaktadır. Bu sonuçlar çerçevesinde ifade edilebilir ki, Türkiye'de etkinlik sorunu yaşayan bankalar, girdi-çıktı tercihlerini, sektördeki diğer başarılı bankaların performanslarını dikkate alarak yeniden gözden geçirmelilerdir. Son olarak dikkatleri çekmek de fayda var ki, yukarıda bahsi geçen sonuçlar, VZA ile hesaplanmış skorlar olup, ekonometrik özelliklere sahip Stokastik Sınır Analizi (SSA) ile de ilerleyen araştırmalarda test edilebilir.

\section{KAYNAKÇA}

SUFIAN, F. (2009). Determinants of Bank Efficiency During Unstable Macroeconomic Environment: Empirical Evidence from Malaysia. Research in International Business and Finance, 23, 54-77.

ISIK, I. (2008). Productivity, technology and efficiency of de novo banks: A counter evidence from Turkey. Journal of Multinational Financial Management, 18, 427-442.

REZITIS, N. A., (2007). Efficiency and Productivity Effects of Bank Mergers: Evidence from the Greek Banking Industry. Economic Modelling , 25, 236-254.

ISIK, I., \& Hassan M.K. (2002). Technical, Scale and Allocative Efficiencies of Turkish Banking Industry. Journal of Banking \& Finance, 26, 719-766.

DAS, A., RAY S.C., \& NAG A. (2009). Labor-use efficiency in Indian banking : A branchlevel analysis. Omega, 37, 411-425.

MERCAN, M., ARNOLD R., REHA Y., \& Ahmet B.E. (2003). The Effect of Scale and Mode of Ownership on the Financial Performance of the Turkish Banking Sector: Results of a DEA-Based Analysis. Socio-Economic Planning Sciences, 37, 185-202. 
CHEN, X., Michael S. \& Brown, K. (2005). Banking efficiency in China: Application of DEA to pre- and postderegulation eras: 1993-2000. China Economic Review 16, 229-245

HAVRYLCHYK, O. (2006). Efficiency of the Polish Banking Industry: Foreign Versus Domestic Banks. Journal of Banking \&Finance, 30, 1975-1996.

MAMATZAKİS, E., STAİKOURAS, C., \& KOUTSOMANOLİ-FİLIPPAKİ, A., (2008), Cost efficiency of the banking industry in the South Eastern European region. Journal of International Financial Markets, Institutions and Money, 18, 483-497.

ERKOC, Taptuk Emre. (2012). Estimation Methodology of Economic Efficiency: Stochastic Frontier Analysis vs Data Envelopment Analysis. International Journal of Academic Research in Economics and Management Sciences, 1.1 : 1-23.

JACKSON, P.M., Fethi, M.D. (2000). Evaluating the technical efficiency of Turkish commercial banks: An Application of DEA and Tobit Analysis, University of Leicester, Mimeo.

JACKSON, M.P, Fethi M.D., \& Đnal, G. (1998). Efficiency and Productivity Growth in Turkish Commercial Banking Sector: A Non-parametric Approach. European Symposium on Data Envelopment Analysis-Recent Developments and Applications.

BERGER, A.N., Hunter, W. ve Timme, S.. (1993). The Efficiency of Financial Institutions: A Review and Preview of Research Past, Present and Future. Journal of Banking and Finance, 17, 221-249.

MAUDOS, J. ve Pastor, J. M.. (2003). Cost and Profit Efficiency in Banking: An International Comparison of Europe, Japan and the USA. Applied Economics Letters, 8, 383-387.

İNAN, E.A.. (2000). Banka Etkinliğinin Ölçülmesi ve Düşük Enflasyon Sürecinde Bankacılıkta Etkinlik. Bankacılar Dergisi, 34, 85-86.

Türkiye Bankalar Birligi, 2005, "Türkiye’de Finansal Sektör ve Bankac1lık Sistemi”

TOLON, Metehan, "Ticari Bankalarda Pazarlama Stratejilerinin Uygulanmas1 ve Türkiye'deki Ticari Bankalar Üzerine Bir Alan Çalışması”, Verimlilik Dergisi, 2004/4, s.6364. 